\title{
Comparative study of natural radiation exposure to the public in three uranium and oil regions of Cameroon
}

\author{
Saïdou $^{1,2 \star}$, P. Ele Abiama ${ }^{1,2}$ and S. Tokonami ${ }^{3}$ \\ 1 Nuclear Physics Laboratory, Faculty of Science, University of Yaoundé I, P.O. Box 812, Yaoundé, Cameroon. \\ 2 Nuclear Technology Section, Institute of Geological and Mining Research, P.O. Box 4110, Yaoundé, Cameroon. \\ 3 Department of Radiation Physics, Institute of Radiation Emergency Medicine, Hirosaki University, Hirosaki City, Aomori 036-8564, Japan.
}

Received 30 March 2015 - Accepted 17 July 2015

\begin{abstract}
The objective of this work is to compare natural radiation exposure to the public in the uranium regions of Poli and Lolodorf and the oil region of Bakassi in Cameroon. From some reported studies on natural radiation exposure in Cameroon, the radiation risk was determined. Activity concentrations, external radiation, and the ingestion and inhalation dose of each of the above regions were compared with the world average value given by the United Nations Scientific Committee on the Effects of Atomic Radiation (UNSCEAR). From the total dose, the radiation risk of each region was calculated and compared with the world average value. The specific case of indoor radon exposure was particularly considered. The radiation risk attributed to the indoor radon exposure was compared with the lung cancer rate in Cameroon as given by the International Agency for Research on Cancer (IARC). In conclusion, the local risks are elevated but not necessarily representative of the country as a whole.
\end{abstract}

Keywords: natural radioactivity / radiation dose / indoor radon / radiation risk / lung cancer

\section{Introduction}

There have been many surveys to determine the background levels of radionuclides in soil in Cameroon. Saïdou et al. (2011) reported radioactivity measurements and a total dose assessment in the uranium region of Poli in Northern Cameroon. They concluded that most of the total dose assessed is attributable to the intake of radon and high levels of ${ }^{210} \mathrm{Po}$ and ${ }^{210} \mathrm{~Pb}$ contained in vegetables, food items which constitute an important part of the diet in Northern Cameroon. Consequently, transfer of uranium ore from underground to the surface might lead to an increased dose for the population of Poli through a higher deposition of ${ }^{222} \mathrm{Rn}$ decay products on leafy vegetables. Indoor radon measurements were carried out in the uranium regions of Poli and Lolodorf (Saïdou et al., 2014). The results highlighted high levels of indoor radon in these regions. Saïdou et al. (2015) reported a study on the radiological exposure of members of the public in the oil-bearing Bakassi Peninsula. The results show high exposure of members of the public to natural radiation. Elevated indoor radon concentrations due to building habits (building materials, ventilation and type of floor) were observed and high exposure to ${ }^{210}$ Po due to the dietary habits of the local population, mainly consisting of seafood, was found. Ele Abiama et al. (2010, 2012) studied the high background radiation and internal / external radiation exposure to the public of the uranium region of Lolodorf

\footnotetext{
* saidous2002@yahoo.fr
}

in Southwestern Cameroon. These studies evidenced high radioactivity occurring in the uranium region of Lolodorf and showed that computed doses from intake of naturally occurring radionuclides are significantly high.

The objective of the present study is to compare natural radioactivity and the corresponding radiation dose and risk in three uranium and oil regions of Cameroon, namely Poli, Lolodorf and Bakassi. These regions were selected due to the uranium and oil deposits occurring in these areas. Data on activity concentrations and radiation doses come from previously reported studies on the above regions (Saïdou et al., 2011, 2014, 2015; Ele Abiama et al., 2010, 2012) and will be used to determine the corresponding radiation risk. The specific case of indoor radon exposure will particularly be considered. Radiation risk attributed to indoor radon exposure will be compared with the lung cancer rate in Cameroon as given by the International Agency for Research on Cancer (IARC, 2008).

\section{Materials and methods}

\subsection{Activity measurements}

\subsubsection{Radioactivity in soil}

A total of 20, 15 and 15 soil samples were respectively collected in the uranium regions of Poli and Lolodorf and the 


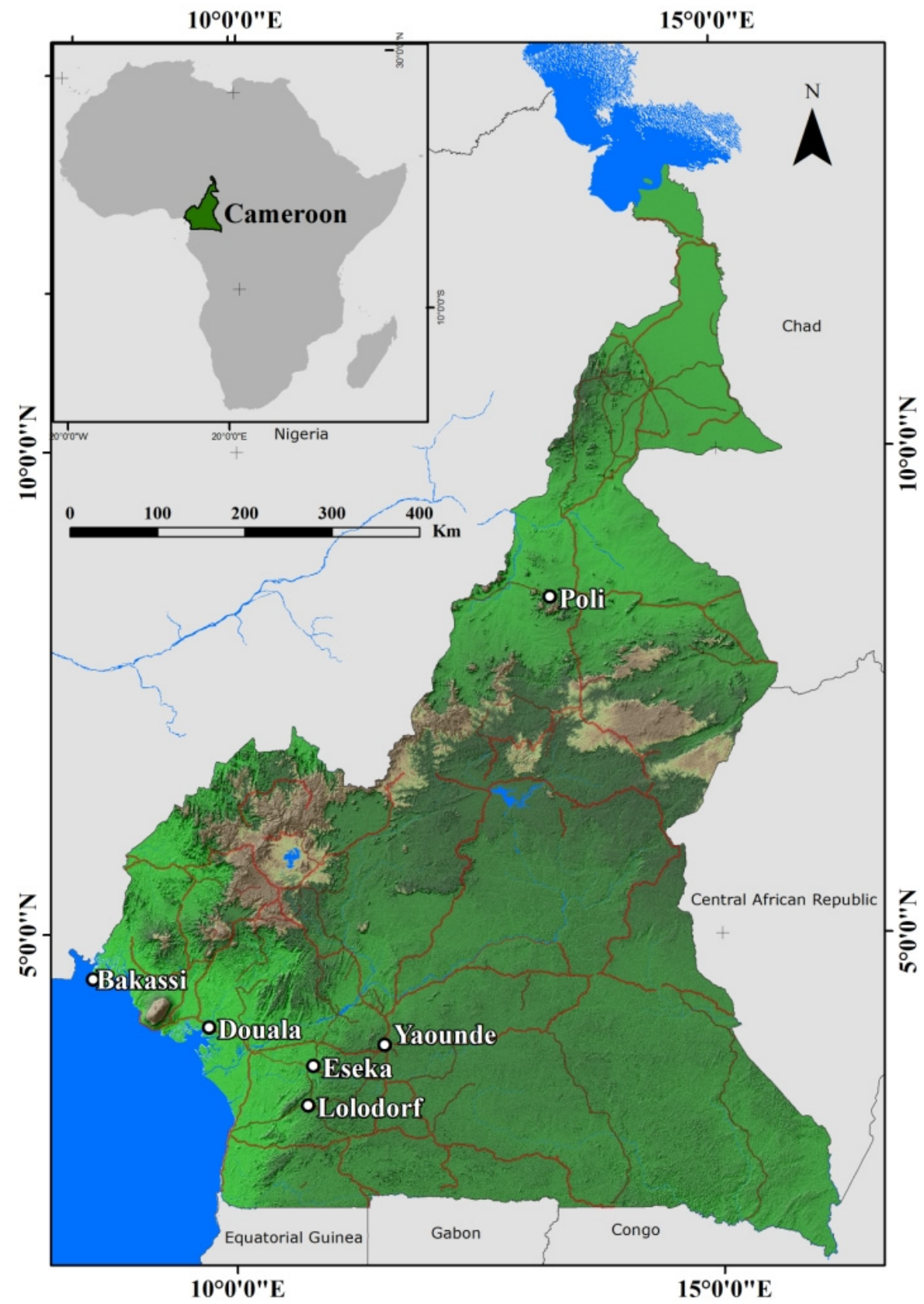

Figure 1. Location of the study areas (Poli, Lolodorf and Bakassi) in Cameroon.

oil region of Bakassi, shown in Figure 1. To measure radioactivity in these samples, alpha and gamma spectrometry were used. Hyper-Pure Germanium (HPGe) detectors were used for gamma spectrometry and Passivated Implanted Planar Silicon (PIPS) detectors for alpha spectrometry for samples collected in the uranium regions of Poli and Lolodorf. A sodium iodide ( $\mathrm{NaI})$ detector was used to measure radioactivity in samples collected in Bakassi. Uncertainty assessment of activity concentrations is well described in Saïdou et al. (2007, 2008). More details about the sampling and conditioning, characteristics, energy and efficiency calibration of the above detectors can be found in references (Saïdou et al., 2007, 2008, 2011; Ele Abiama et al., 2010, 2012).

\subsubsection{Radioactivity in foodstuffs}

Alpha and gamma spectrometry were used to measure radioactivity in foodstuffs. Alpha spectrometry using automated borate fusion and sequential extraction and exchange chromatography were used to determine the uranium and thorium isotopes in the samples collected in Poli (Saïdou et al., 2008). Alpha spectrometry using microwave acid digestion under pressure for sample mineralization was used to measure ${ }^{210} \mathrm{Po}$ in the foodstuffs collected in Poli and Bakassi (Saïdou et al., 2007). Gamma spectrometry was also used to measure radioactivity in the foodstuffs collected in Poli, Lolodorf and Bakassi. The types of foodstuffs collected are given in Table 2. 
Table 1. Air kerma conversion coefficients $\left[\left(\mathrm{nGy} \cdot \mathrm{h}^{-1}\right) /\left(\mathrm{Bq} \cdot \mathrm{kg}^{-1}\right)\right]$ of radioactivity in soil (UNSCEAR, 1993).

\begin{tabular}{lc}
\hline Radionuclides & $\begin{array}{c}\text { Air kerma conversion coefficient } \\
\left(\mathbf{n G y} \cdot \mathbf{h}^{-\mathbf{1}}\right) /\left(\mathbf{B q} \cdot \mathbf{k g}^{-\mathbf{1}}\right)\end{array}$ \\
\hline${ }^{238} \mathrm{U}$ series & 0.46 \\
${ }^{232} \mathrm{Th}$ series & 0.60 \\
${ }^{40} \mathrm{~K}$ & 0.042 \\
\hline
\end{tabular}

Uncertainty assessment of activity concentrations is well described in Saïdou et al. (2007, 2008). More details about the sampling and conditioning, the characteristics of the detectors and their energy and efficiency calibration are given in references (Saïdou et al., 2011, 2015; Ele Abiama et al., 2012).

\subsubsection{Radon in dwellings}

Electret ionization chambers (EICs) were exposed for three months to measure indoor radon in the above regions. Respectively 100, 50 and 15 dwellings were considered for the uranium regions of Poli and Lolodorf and the oil region of Bakassi. Radon concentrations were determined using equation (1):

$$
\begin{aligned}
C_{R n}\left(B q . m^{-3}\right) & =37 \times\left(\frac{I-F}{C F . D}-B G\right) f_{\text {corr }}^{\text {att }}\left(p C i . l^{-1}\right) \\
C F & =A+B \frac{I+F}{2}
\end{aligned}
$$

where $I$ and $F$ are the initial and final voltages of the electret expressed in volts [V], CF is the calibration factor $\left[\mathrm{V} / \mathrm{pCi.} \mathrm{l}^{-1}\right.$ days], $D$ is the duration of the exposure [days], $B G$ is the background due to the ambient dose expressed in radon equivalent concentration $\left[\mathrm{pCi.} \mathrm{l}^{-1}\right]$, and $f_{\text {corr }}^{\text {att }}$ is the correction factor, taking into account the dwelling's altitude (alt) above sea level. Uncertainty assessment of radon concentrations is well described in Saïdou et al. (2014).

\subsection{Radiation dose assessment}

\subsubsection{External radiation dose}

The corresponding ground radiation dose in the uranium regions of Poli and Lolodorf and the oil region of Bakassi was assessed using the dose conversion factors in Table 1 given by UNSCEAR (1993) for ${ }^{238} \mathrm{U}$ and ${ }^{232} \mathrm{Th}$ series and ${ }^{40} \mathrm{~K}$. It is given by the following equation:

$$
\mathrm{E}_{\mathrm{ext}}=\mathrm{F}_{\mathrm{c}} \times\left[\left(1-\mathrm{F}_{\mathrm{occ}}\right)+F_{o c c} F_{b}\right] \times \sum_{i=1}^{3} A_{i} \times(K C F)_{i} t
$$

where $F_{c}$ is the conversion coefficient of $0.7 \mathrm{mSv}_{\mathrm{mGy}}{ }^{-1}$ used to determine the corresponding effective annual dose, and $F_{\text {occ }}$ is the indoor occupancy factor of 0.6 , which implies that people spend $40 \%$ of the time outdoors. However, since the materials used in the construction of most of these buildings also contain radionuclides, the average factor $F_{b}$ of 1.4 was applied to take into account their contribution and estimate the indoor dose rate. $A_{i}$ are average activity concentrations of ${ }^{238} \mathrm{U},{ }^{232} \mathrm{Th}$, and ${ }^{40} \mathrm{~K}$, and $(K C F)_{i}$ are corresponding air kerma conversion factors given in Table 1.

\subsubsection{Ingestion dose}

The ingestion dose is given by the following equation:

$$
E_{\text {ing }}=\sum_{i} A_{\text {ing }}^{i} \times m_{\text {ing }} \times e_{\text {ing }}^{i} \times t .
$$

$A_{\text {ing }}^{i}$ is the average activity concentration of the $i$ radionuclide in Bq. $\mathrm{kg}^{-1}, m_{\text {ing }}$ is the mass of the daily ingested food in $\mathrm{kg}$, $e_{i n g}^{i}$ is the ingestion dose conversion factor of the same radionuclide in $\mathrm{Sv}_{\mathrm{Bq}} \mathrm{Bq}^{-1}$ and $t$ is the exposure time in days. The daily consumption mass of ingested food is given in Table 2. The ingestion dose conversion factors used in the present work were calculated by the ICRP $(1994,1995)$.

\subsubsection{Inhalation dose}

The inhalation dose from radon and its daughters is given by the following equation (UNSCEAR, 2000):

$$
E_{\text {inh }}=A_{\text {inh }} \times e_{\text {inh }} \times F_{o c c} \times F_{e q} \times t .
$$

$A_{i n h}$ is the median radon concentration, $e_{i n h}$ is the inhalation dose conversion factor of $9 \mathrm{nSv} /\left(\mathrm{Bq} . \mathrm{h}_{\mathrm{m}} \mathrm{m}^{-3}\right), F_{\text {occ }}$ is the occupancy factor of 0.6 for the studied areas, $F_{e q}$ is the equilibrium factor considered of 0.4 and $t$ corresponds to a year expressed in hours. The occupancy factor was derived from an in situ inquiry performed in the studied areas during field work. The equilibrium factor used is the default value given by UNSCEAR and will be measured for the study areas and reported very soon.

\section{Radiation risk assessment}

\subsection{Radiation risk due to natural radioactivity}

According to the ICRP in the low-dose range, it is scientifically plausible to assume that the incidence of cancer or heritable effects will rise in direct proportion to an increase in the equivalent dose in the relevant organs and tissues. The ICRP proposed nominal probability coefficients for detrimentadjusted cancer risk as $5.5 \times 10^{-2} \mathrm{~Sv}^{-1}$ for the whole population and $4.1 \times 10^{-2} \mathrm{~Sv}^{-1}$ for adult workers (ICRP, 2007). Radiation risk is given by the equation:

$$
R R=5.5 \times 10^{-2} \times\left(E_{\text {ext }}+E_{\text {inh }}+E_{\text {ing }}\right)
$$

where $E_{\text {ext }}, E_{\text {inh }}$ and $E_{\text {ing }}$ given above are expressed in Sv.

One should note that ICRP coefficients are not given to evaluate a risk of developing cancers. They were obtained from a long-term survey of Hiroshima and Nagasaki survivors and therefore express the life risk of a specific population. Thus, this radiation risk assessment should be cautiously considered because the calculations done here with the ICRP data are just to have a broad overview of the risk. 
Table 2. Daily consumption mass of ingested food in the Poli, Lolodorf and Bakassi areas (Saïdou et al., 2011, 2015; Ele Abiama et al., 2012).

\begin{tabular}{lcc}
\hline Region & Foodstuff & $\begin{array}{c}\text { Daily consumption } \\
\text { mass (g) }\end{array}$ \\
\hline Poli & Flour of maize & 850 \\
& Groundnut paste & 25 \\
& Beef & 100 \\
& Leaf powder (baobab/ "lalo") or dry gombo & 30 \\
White bean & 20 \\
& Water (cooking + drinking) & 4500 \\
& Groundnuts & 82 \\
& Plantain & 274 \\
& Cassava leaves & 137 \\
Cassava roots & 274 \\
Cocoyam & 164 \\
& Tapioca (cassava by-product) & 400 \\
& Fish & 200 \\
& Shrimps & 50 \\
& Waterleaf & 50 \\
& Eru leaf & 50 \\
\hline
\end{tabular}

\subsection{Radiation risk due to indoor radon}

Epidemiological studies of occupational exposure of miners and residential exposure of the public have provided evidence of the risks of lung cancer following inhalation of radon and its progeny. For radon exposure the ICRP (2011a) recommended that a lifetime excess absolute risk (LEAR) of $5 \times 10^{-4}$ per WLM should be used as the nominal probability coefficient for radon- and radon-progeny-induced lung cancer, updating the Publication 65 (ICRP, 1993) value of $2.8 \times 10^{-4}$ per WLM.

$$
\mathrm{WLM}=6.37 \times 10^{5} /\left(\mathrm{F}_{\mathrm{eq}} \cdot \mathrm{Bq} \cdot \mathrm{h} \cdot \mathrm{m}^{-3}\right) .
$$

The lifetime excess absolute risk due to indoor radon used in the present study is given by the following equation:

$$
\mathrm{LEAR}=5 \times 10^{-4} \times \mathrm{WLM}^{-1}=7.85 \times 10^{-10}\left(\mathrm{~F}_{\mathrm{eq}} \mathrm{Bq} \cdot \mathrm{h} \cdot \mathrm{m}^{-3}\right) .
$$

To assess the LEAR of each investigated area, occupancy and equilibrium factors of 0.6 and 0.4 , respectively, were used. The risk coefficients used to analyze the case of the uranium and oil regions of Cameroon come from the results of epidemiological studies of populations exposed to ionizing radiation. There are sources of uncertainty in analyzing the results of these epidemiological studies, specifically the uncertainties in information on health effects, and in information on exposure, dose assessment and the dose-response model in risk assessment. There are also uncertainties in transferring risk quantities from given studies to other exposure conditions or populations of interest, uncertainties of selected risk evaluations. More details are given in UNSCEAR (2012).

\section{Results and discussion}

\subsection{Activity measurements}

\subsubsection{Radioactivity in soil}

The average activity concentrations of ${ }^{238} \mathrm{U},{ }^{232} \mathrm{Th}$ and ${ }^{40} \mathrm{~K}$ in soil of the uranium regions of Poli and Lolodorf and the oil region of Bakassi are given in Table 3. It can be noted that radioactivity level of the region of Poli is low compared with the world average activity concentrations as estimated by UNSCEAR (2000): $33 \mathrm{~Bq} \cdot \mathrm{kg}^{-1}$ for ${ }^{238} \mathrm{U}, 45 \mathrm{~Bq} \cdot \mathrm{kg}^{-1}$ for ${ }^{232} \mathrm{Th}$ and $420 \mathrm{~Bq} \cdot \mathrm{kg}^{-1}$ for ${ }^{40} \mathrm{~K}$. This is consistent since the uranium mining and milling processes of the Kitongo deposits have not yet started. Finally, the fact that radioactivity is low in the Poli region does not infer the absence of a uranium deposit in Kitongo. According to Saïdou et al. (2011), the uranium ores are probably deeply situated. The above worldwide average activity concentrations were estimated by UNSCEAR (2000) using natural radiation survey data from countries including uranium mining regions, although they are not well represented.

In the uranium region of Lolodorf, the high concentration of ${ }^{226} \mathrm{Ra}$ observed in soil samples can be explained by the presence of uranium-bearing radiogenic heavy minerals. The very high concentration of ${ }^{232} \mathrm{Th}$ indicates the presence of thoriumbearing minerals in the soil samples (Ele Abiama et al., 2010). The average values of the activity concentrations of ${ }^{226} \mathrm{Ra}$, ${ }^{232} \mathrm{Th}$ and ${ }^{40} \mathrm{~K}$ in different studied locations are much higher than the world average values (UNSCEAR, 2000).

In the oil region of Bakassi, the activity concentrations of ${ }^{238} \mathrm{U},{ }^{232} \mathrm{Th}$ and ${ }^{40} \mathrm{~K}$ are lower than the average activity observed in the world (UNSCEAR, 2000). The level of natural radioactivity is in agreement with what can be expected when there is no contamination. Finally, no radioactive contamination is evidenced due to the presence of offshore production platforms in the Bakassi Peninsula (Saïdou et al., 2015). 
Table 3. Average activity concentrations of ${ }^{238} \mathrm{U},{ }^{232} \mathrm{Th}$ and ${ }^{40} \mathrm{~K}$ in 20,15 and 15 soil samples collected, respectively, in the uranium regions of Poli and Lolodorf and the oil region of Bakassi (Saïdou et al., 2011, 2015; Ele Abiama et al., 2010). Standard uncertainties are expressed for $k=1$, using the approach developed in ISO (1995).

\begin{tabular}{|c|c|c|c|}
\hline Study area & Radionuclide & $\begin{array}{c}\text { Mean activity } \\
\left(\mathrm{Bq}^{\mathrm{kgg}}{ }^{-1}\right)\end{array}$ & $\begin{array}{c}\text { Minimum-Maximum activity } \\
\left(\mathrm{Bq}^{\mathrm{k}} \mathrm{kg}^{-1}\right)\end{array}$ \\
\hline \multirow[t]{3}{*}{ Poli } & ${ }^{238} \mathrm{U}$ & $23.6 \pm 0.6$ & $12.4 \pm 1.5-57 \pm 4$ \\
\hline & ${ }^{232} \mathrm{Th}$ & $28 \pm 0.6$ & $14.6 \pm 1.5-58 \pm 5$ \\
\hline & ${ }^{40} \mathrm{~K}$ & $506 \pm 3$ & $112 \pm 4-1124 \pm 27$ \\
\hline \multirow[t]{3}{*}{ Lolodorf } & ${ }^{238} \mathrm{U}$ & $130 \pm 10$ & $60 \pm 10-270 \pm 20$ \\
\hline & ${ }^{232} \mathrm{Th}$ & $390 \pm 30$ & $100 \pm 10-700 \pm 50$ \\
\hline & ${ }^{40} \mathrm{~K}$ & $850 \pm 70$ & $370 \pm 20-1530 \pm 110$ \\
\hline \multirow[t]{3}{*}{ Bakassi } & ${ }^{238} \mathrm{U}$ & $19 \pm 4$ & $15.6 \pm 3.1-23.2 \pm 4.6$ \\
\hline & ${ }^{232} \mathrm{Th}$ & $32 \pm 6$ & $26.5 \pm 5.3-37.8 \pm 7.5$ \\
\hline & ${ }^{40} \mathrm{~K}$ & $110 \pm 22$ & $93 \pm 18-138 \pm 27$ \\
\hline
\end{tabular}

Table 4. Activity concentration ranges of ${ }^{226} \mathrm{Ra},{ }^{228} \mathrm{Ra},{ }^{210} \mathrm{~Pb},{ }^{210} \mathrm{Po}$ and ${ }^{40} \mathrm{~K}$ in foodstuffs sampled in the uranium regions of Poli and Lolodorf and the oil region of Bakassi (Saïdou et al., 2011, 2015; Ele Abiama et al., 2012). Each activity concentration is averaged from three different samples of the same type of foodstuff in Table 2. Standard uncertainties are expressed for $k=1$.

\begin{tabular}{lcc}
\hline Study area & Radionuclide & $\begin{array}{c}\text { Activity concentration } \\
\left(\mathbf{B q . k g}^{-1}\right)\end{array}$ \\
\hline Poli & ${ }^{226} \mathrm{Ra}$ & $0.04 \pm 0.008-2.3 \pm 0.6$ \\
& ${ }^{210} \mathrm{~Pb}$ & $1.9 \pm 0.4-29.7 \pm 2.3$ \\
& ${ }^{210} \mathrm{Po}$ & $0.24 \pm 0.05-28.0 \pm 0.8$ \\
Lolodorf & ${ }^{40} \mathrm{~K}$ & $94 \pm 2-677 \pm 9$ \\
& ${ }^{22} \mathrm{Ra}$ & $0.04 \pm 0.01-11 \pm 3$ \\
& ${ }^{22} \mathrm{Ra}$ & $0.2 \pm 0.06-13 \pm 4$ \\
Bakassi & ${ }^{40} \mathrm{~K}$ & $48 \pm 2-234 \pm 4$ \\
& ${ }^{226} \mathrm{Ra}$ & $1.2 \pm 0.3-35 \pm 15$ \\
& ${ }^{210} \mathrm{~Pb}$ & $1.6 \pm 0.3-64 \pm 16$ \\
& ${ }^{210} \mathrm{Po}$ & $0.33 \pm 0.04-122 \pm 4$ \\
& ${ }^{40} \mathrm{~K}$ & $111 \pm 9-1880 \pm 32$ \\
\hline
\end{tabular}

\subsubsection{Radioactivity in foodstuffs}

The activity concentrations of the main natural radionuclides in foodstuffs are summarized in Table 4. In the uranium region of Poli, the activities of ${ }^{210} \mathrm{Po}$ and ${ }^{210} \mathrm{~Pb}$ were higher in vegetables due to the atmospheric deposition of radon decay products. These vegetables are frequently consumed by the inhabitants of Poli. Consequently, transfer of uranium ore from underground to the surface might lead to an increased dose for the population of Poli through a higher deposition of ${ }^{222} \mathrm{Rn}$ decay products on leafy vegetables (Saïdou et al., 2011). Moreover, weathering of material stemming from excavations during exploration and development works of the Kitongo deposit in Poli could contribute to increasing the radiation dose to the public. On the other hand, in the uranium region of Lolodorf, the activity concentrations of ${ }^{226} \mathrm{Ra}$ and ${ }^{228} \mathrm{Ra}$ in each type of food were much higher than the world average values as given in UNSCEAR (2000). This can be explained by the high level of these radionuclides in soil, the specific radionuclide uptake by some food items and their high consumption (Ele Abiama et al., 2012). No activity concentrations
Table 5. Arithmetic, geometric and median concentrations of indoor radon in the uranium regions of Poli and Lolodorf and the oil region of Bakassi (Saïdou et al., 2014, 2015) compared with the world average value given by UNSCEAR (2000).

\begin{tabular}{lccc}
\hline $\begin{array}{l}\text { Study } \\
\text { area }\end{array}$ & $\begin{array}{c}\text { Arithmetic mean } \\
\left(\mathbf{B q} \cdot \mathbf{m}^{-\mathbf{3}}\right)\end{array}$ & $\begin{array}{c}\text { Geometric mean } \\
\left(\mathbf{B q} \cdot \mathbf{m}^{\mathbf{3}}\right)\end{array}$ & $\begin{array}{c}\text { Median } \\
\left(\mathbf{B q} \cdot \mathbf{m}^{-\mathbf{3}}\right)\end{array}$ \\
\hline Poli & 294 & 200 & 165 \\
Lolodorf & 735 & 318 & 331 \\
Bakassi & 1280 & & 907 \\
World & 40 & 30 & - \\
\hline
\end{tabular}

of ${ }^{210} \mathrm{P}$ and ${ }^{210} \mathrm{~Pb}$ in foodstuffs are currently reported for the uranium region of Lolodorf.

Finally, in Bakassi, high activity concentrations of ${ }^{210} \mathrm{Po}$ and sometimes ${ }^{210} \mathrm{~Pb}$ were observed, notably in seafood (fish, shrimps). ${ }^{210} \mathrm{~Pb}$ and ${ }^{210} \mathrm{Po}$ are very radiotoxic and present in relatively high concentrations in the marine biota due to their enhanced bioaccumulation and strong affinity for binding with certain internal tissues.

\subsubsection{Indoor radon}

As summarized in Table 5, the indoor radon concentrations in Poli, Lolodorf and Bakassi range, respectively, between 29-2240 Bq. ${ }^{-3}, 24-4390$ Bq. ${ }^{-3}$ and $51-4230$ Bq. $\mathrm{m}^{-3}$ with corresponding mean values of $294 \mathrm{~Bq} \cdot \mathrm{m}^{-3}, 735 \mathrm{~Bq} \cdot \mathrm{m}^{-3}$ and $1280 \mathrm{~Bq} \cdot \mathrm{m}^{-3}$ and median values of $165 \mathrm{~Bq} \cdot \mathrm{m}^{-3}$, $331 \mathrm{~Bq} \cdot \mathrm{m}^{-3}$ and $907 \mathrm{~Bq} \cdot \mathrm{m}^{-3}$. Twenty percent of houses in Poli, $50 \%$ in Lolodorf and $60 \%$ in Bakassi have indoor radon above the ICRP reference level of $300 \mathrm{~Bq} \cdot \mathrm{m}^{-3}$ (ICRP, 2011b), requiring radon mitigation (Saïdou et al., 2014, 2015). This level of exposure, largely above the world average value of $40 \mathrm{~Bq} . \mathrm{m}^{-3}$ estimated by UNSCEAR (2000), probably has an impact on human health, leading to an increase in the probability of developing lung cancer (Darby et al., 2005).

Finally, the high indoor radon distribution observed in the uranium regions of Poli and Lolodorf and the oil region of Bakassi could stem from the use of soil bricks as building materials and ground as a floor type. Moreover, a non-negligible fraction of dwellings is not ventilated. One should note that the bricks are made using soil collected from the study areas. 
Table 6. Radiation dose components of the uranium regions of Poli and Lolodorf and the oil region of Bakassi compared with the world average values as given by UNSCEAR (2000). Cosmic ray radiation is not taken into account in the calculations.

\begin{tabular}{lcccc}
\hline Exposure pathway & Poli & Lolodorf & Bakassi & World \\
\hline External irradiation $\left(\mathrm{mSv} \cdot \mathrm{y}^{-1}\right)$ & 0.6 & 0.7 & 0.3 & 0.5 \\
Ingestion $\left(\mathrm{mSv} \cdot \mathrm{y}^{-1}\right)$ & 2.2 & 0.7 & 4.8 & 0.3 \\
Inhalation $\left(\mathrm{mSv} \cdot \mathrm{y}^{-1}\right)$ & 3.1 & 6.2 & 17.2 & 1 \\
Total dose $\left(\mathrm{mSv} \cdot \mathrm{y}^{-1}\right)$ & 5.9 & 7.6 & 22.3 & 1.8 \\
\hline
\end{tabular}

Table 7. Annual excess risk due to natural radiation exposure in the uranium regions of Poli and Lolodorf and the oil region of Bakassi compared with the world average value.

\begin{tabular}{lc}
\hline Study area & Radiation risk $(\%)$ \\
\hline Poli & 0.03 \\
Lolodorf & 0.04 \\
Bakassi & 0.1 \\
World & 0.01 \\
\hline
\end{tabular}

\subsection{Radiation dose assessment}

The main exposure pathways are displayed in Table 6: external radiation (ground, inhalation and ingestion). The average values of the total dose for the uranium-bearing regions of Poli and Lolodorf and the oil region of Bakassi are high compared with the world average value of $1.8 \mathrm{mSv}^{-1} \mathrm{y}^{-1}$. The difference from the world average value is easily explained by the dietary habits of the local population and the high level of indoor radon exposure, mainly attributed to the building habits (building materials, ventilation and floor type). The values of the radiation dose shown in Table 6 can be compared with the dose to the public in the high natural radiation areas of Ramsar in Iran and Kerala in India. People in some areas of Ramsar, a city in northern Iran, receive an annual radiation absorbed dose from background radiation that is up to $260 \mathrm{mGy} \cdot \mathrm{y}^{-1}$, and average exposure rates to the public are about $10 \mathrm{mGy}^{-1}$ (Ghiassi-nejad et al., 2002). Some areas in India have high levels of natural radiation due to the presence of monazite $(9 \%$ thorium and $0.3 \%$ uranium). In Kerala, on the southwest coast of India, the annual average dose to the public is $15-25 \mathrm{mGy}$ (Kesavan, 1997).

\subsection{Radiation risk assessment}

The annual excess radiation risk of the uranium regions of Poli and Lolodorf and the oil region of Bakassi was calculated from the radiation dose of each region. As shown in Table 7, the radiation risk of each region is higher than the average value corresponding to the rest of the world. This result was expected because the radiation risk increases with the radiation dose. This radiation risk assessment should be cautiously considered because calculations made with the ICRP data are just to have a broad overview of the risk, and to compare with the natural cancer rate. According to the World Health Organization (IARC, 2008), the age-standardized rate of cancer deaths in Cameroon in 2002 was 150/100 000 persons/year.

Table 7 shows that the annual excess risk due to natural radiation in Poli, Lolodorf and Bakassi is respectively 30/100000, 40/100000 and 100/100000, i.e. less than the age-standardized rate of cancer deaths
Table 8. Annual excess risk due to indoor radon exposure in the uranium regions of Poli and Lolodorf and the oil region of Bakassi compared with the world average value.

\begin{tabular}{lc}
\hline Exposure area & Radiological risk $(\%)$ \\
\hline Poli & 0.027 \\
Lolodorf & 0.05 \\
Bakassi & 0.15 \\
World & 0.007 \\
\hline
\end{tabular}

of 150/100 000 in Cameroon. The annual excess risk in Bakassi is particularly high; this is mainly justified by the high exposure of members of the public to indoor radon (see below).

\subsubsection{Radiation risk assessment: the case of indoor radon}

Extensive measurements of radon concentrations in homes show that although concentrations vary widely, radon is universally present, raising concerns that radon in homes increases the lung cancer risk for the general population (NRC, 1999). Radon is the second cause of lung cancer after smoking. Current estimates of the worldwide proportion of lung cancer due to radon ranges between 3-14\% (WHO, 2009). Epidemiological studies have provided strong evidence of an association between indoor radon exposure and lung cancer, even at the relatively low radon levels commonly found in residential buildings (Darby et al., 2005). The analyses indicate that the lung cancer risk increases proportionally with increasing radon exposure (WHO, 2009). This risk is about $20 \%$ per $100 \mathrm{~Bq} \cdot \mathrm{m}^{-3}$. Radon in the home accounts for about $9 \%$ of deaths from lung cancer and about $2 \%$ of all deaths from cancer in Europe (Darby et al., 2005). According to the WHO, $2.3 \%$ of all deaths in the world were attributed to lung cancer in 2008 , leading to about 1.38 million lung cancer victims worldwide (IARC, 2008).

In Central African countries such as Cameroon, the ageadjusted death rate for lung cancer was 2.7/100000 persons/year in 2008 (IARC, 2008). It is known that smoking is the first cause of lung cancer. According to the National Institute of Statistics in Cameroon, in 2015 there are 1.1 million smokers in the country (13.9\% of Cameroonian men and $4.3 \%$ of Cameroonian women are smokers, on average $8.9 \%$ of adults).

Based on the annual excess risk values as shown in Table 8, we can still make the point that a comparison of local radiological risks with national cancer incidence data allows us to conclude that the local risks are elevated but not necessarily representative of the country as a whole.

This value of risk should be cautiously considered, particularly in Bakassi where radon was measured in only 
15 dwellings, meaning that the radon measurements are not representative enough of the investigated area. Thus, extensive measurements are needed for a reliable comparison. One should note that from sampling and radioactivity measurements to radiation dose and risk assessment, substantial uncertainties are expected, influencing the values to compare.

Data were obtained by calculating the dose from inhalation to the ICRP detriment. For instance, the risk in Poli should be half of the total risk (Table 7) since the dose from inhalation is half of the total dose. Moreover, if the calculation is done in that way, it is important to note that the ICRP detriment is calculated for whole-body cancer, whereas radon causes only lung cancers. The models used to calculate the risks due to natural radiation exposure and due to radon are not the same. Moreover, the sources of uncertainty of risk assessment mentioned above should be regarded.

\section{Conclusion}

Comparison of natural radioactivity and the corresponding radiation dose and risk in the uranium regions of Poli and Lolodorf and the oil region of Bakassi was performed. It clearly appears that the radiation dose and radiological risk of each of the studied regions are higher than the world average values. This difference can be explained by the dietary and building habits (building materials, ventilation and floor type) of the populations living in the investigated areas.

A comparison of local radiological risks with national cancer incidence data allows us to conclude that the local risks are elevated but not necessarily representative of the country as a whole.

For the specific case of radon-induced lung cancer, an epidemiological study could be needed after extensive radon and thoron measurements in the whole country, because available data are sparse and not sufficiently representative to perform a strictly valuable comparison.

Acknowledgements. Previously reported studies used in the present work were carried out thanks to collaboration with the Institute of Radiation Physics of Lausanne (IRA), Switzerland, and the National Center for Energy, Sciences and Nuclear Techniques (CNESTEN), Rabat, Morocco. The authors are grateful to the co-authors of these publications.

\section{References}

Darby S. et al. (2005) Radon in homes and risk of lung cancer: collaborative analysis of individual data from 13 European case-control studies, BMJ 330, 223-229.

Ele Abiama P., Owono Ateba P., Ben-Bolie G.H., Ekobena Fouda H.P., El Khoukhi T. (2010) High background radiation investigated by gamma spectrometry of the soil in the southwestern region of Cameroon, J. Environ. Radioact. 101, 739-743.

Ele Abiama P., Ben-Bolie G.H., Amechmachi N., Najibb F., El Khoukhi T., Owono Ateba P. (2012) Annual intakes of ${ }^{226} \mathrm{Ra}$,
${ }^{228} \mathrm{Ra}$ and ${ }^{40} \mathrm{~K}$ in staple foodstuffs from a high background radiation area in the southwest region of Cameroon, J. Environ. Radioact. 110, 59-63.

Ghiassi-nejad M., Mortazavi S.M.J., Cameron J.R., Niroomand-rad A., Karam P.A. (2002) Very high background radiation areas of Ramsar, Iran: Preliminary biological studies, Health Phys. 82 (1), 87-93.

IARC (2008) World Cancer report 2008. IARC Library Cataloguing in Publication Data, Lyon.

ICRP (1993) Protection against ${ }^{222} \mathrm{Rn}$ at home and at work, ICRP Publication 65. Pergamon Press, Oxford.

ICRP (1994) Age-dependant doses to members of the public from intake of radionuclides, part 2. Ingestion dose coefficients, ICRP Publication 67. Pergamon Press, Oxford.

ICRP (1995) Age-dependant doses to members of the public from intake of radionuclides, part 3. Ingestion dose coefficients, ICRP Publication 69. Pergamon Press, Oxford.

ICRP (2007) The 2007 Recommendations of the ICRP. Pergamon Press, Oxford.

ICRP (2011a) Lung Cancer Risk from Radon and Progeny, ICRP Publication 115. Pergamon Press, Oxford.

ICRP (2011b). Radiological Protection against Radon Exposure. Draft Report for Consultation. Pergamon Press, Oxford.

ISO (1995). Guide to the Expression of Uncertainty in Measurement. ISO, Geneva.

Kesavan P.C. (1997) Indian research on high levels of natural radiation: pertinent observations for further studies. In: Proceeding of the 4th International Conference on High Levels of Natural Radiation (ICHLNR), 1996, Beijing (L. Wei, T. Suahara, Z. Tao, Eds.), pp. 111-117.

NRC (1999) BEIR VI Report. Health Risks of Exposure to Radon.National Academy Press, Washington DC.

Saïdou, Bochud F., Laedermann J.P., Buchillier T., Kwato Njock M.G., Froidevaux P. (2007) Calibration of an HPGe detector and self-attenuation correction for ${ }^{210} \mathrm{~Pb}$ : Verification by alpha spectrometry of ${ }^{210} \mathrm{Po}$ in environmental samples, Nucl. Instrum. Meth. A 578, 515-522.

Saïdou, Bochud F., Laedermann J.P., Kwato Njock M.G., Froidevaux P. (2008) A comparison of alpha and gamma spectrometry for environmental radioactivity surveys, Appl. Radiat. Isotopes 66 , 215-222.

Saïdou, Bochud F.O., Baechler S., Kwato Njock M.G., Ngachin M., Froidevaux P. (2011) Natural radioactivity measurements and dose calculations to the public: case of the uranium-bearing region of Poli in Cameroon, Radiat. Meas. 46, 254-260.

Saïdou, Abdourahimi, Tchuente Siaka Y.F., Bouba O. (2014) Indoor radon measurements in the uranium regions of Poli and Lolodorf, Cameroon, J. Environ. Radioact. 136, 36-40.

Saïdou, Abdourahimi, Tchuente Siaka Y.F., Kwato Njock M.G. (2015) Natural Radiation Exposure to the Public in the oil bearing Bakassi Peninsula, Cameroon, Radioprotection 50 (1), 35-41.

UNSCEAR (1993) Sources and effects of ionizing radiation. United Nations publication, New York.

UNSCEAR (2000) Sources and effects of ionizing radiation. UNSCEAR 2000 Report. United Nations publication, Vienna.

UNSCEAR (2012) Sources, effects and risks of ionizing radiation. UNSCEAR 2012 Report. United Nations publication, New York.

WHO (2009) Handbook on Indoor Radon: a public health perspective. Library Cataloguing-in-Publication Data, Geneva. 